Revista Brasileira de Higiene e Sanidade Animal Brazilian Journal of Hygiene and Animal Sanity ISSN: $1981-2965$

\title{
Análise da microbiota fúngica presente em escamas de Bothrops atrox (Serpente:
} Viperidae) criadas em cativeiro

Analysis of the fungal microbiota present in scales of Bothrops atrox (Serpente: Viperidae) maintained in captivity

\section{Erivelton Nascimento Chaves ${ }^{1}$, Leandra Cardoso Pinheiro ${ }^{2}$, Adriano Biancalana ${ }^{3}$,} Fernanda Simas Corrêa Biancalana ${ }^{4}$

Resumo: A serpente Bothrops atrox, é amplamente distribuída no bioma Amazônico e também são mantidas em serpentários, que vêm enfrentando o desafio de aprimorar a criação desses animais. Devido à contaminação e a proliferação de fungos na microbiota das serpentes em cativeiro, a preocupação com o bem estar destes animais é grande, pois doenças micóticas em serpentes podem ser fatais. $\mathrm{O}$ estudo buscou identificar a microbiota fúngica na epiderme de $B$. atrox e evidenciar quais fungos apresenta maior ocorrência na região dorsoventral, assim como determinar se a presença dos fungos está associada ao estágio de vida e ao substrato onde se encontram as serpentes criadas no Centro Amazônico de Herpetologia. A coleta foi realizada em 54 serpentes, com o auxílio de um swab estéril, seguida de semeadura em placas de petri contendo meio de cultura ágar batata. $\mathrm{O}$ crescimento micótico ocorreu em 6 dias na temperatura ambiente. Foram feitas lâminas para a identificação microscópica. Os fungos identificados colonizando as serpentes foram: Penicillium sp (29 amostras), Aspergillus sp (27 amostras), Phoma sp (1 amostra), Rhizopus sp (2 amostras). Os filhotes do ano de 2017 apresentaram maior presença de fungos, do que os filhotes nascidos no ano 2018. O jornal como substrato apresentou mais fungos do que a serragem. Os gêneros Penicillium sp e Aspergillus sp podem provocar patologias como peniciliose e aspergilose, além de manchas na epiderme e nos olhos. De acordo com os resultados sugere-se a aplicação de antifúngicos na epiderme das serpentes, para assim evitar futuros casos de doenças fúngicas.

Palavras chaves: fungos, jararaca, cativeiro.

Abstract: The Bothrops atrox snake, is widely distributed in the Amazon biome and is also kept in serpentariums, which have been facing the challenge of improving the breeding of these animals. Due to the contamination and proliferation of fungi in the microbiota of 
snakes in captivity, the concern for the welfare of these animals is great, since mycotic diseases in snakes can be fatal. The study sought to identify the fungal microbiota in the epidermis of B. atrox and to highlight which fungi are more prevalent in the dorsoventral region, as well as to determine whether the presence of the fungi is associated with the stage of life and the substrate where the snakes raised in the Amazonian Center are found. of Herpetology. The collection was carried out in 54 snakes, with the aid of a sterile swab, followed by sowing in petri dishes containing potato agar culture medium. Mycotic growth occurred in 6 days at room temperature. Slides were made for microscopic identification. The fungi identified colonizing the snakes were: Penicillium sp (29 samples), Aspergillus sp (27 samples), Phoma sp (1 sample), Rhizopus sp (2 samples). The puppies of the year 2017 presented a greater presence of fungi, than the puppies born in the year 2018. The newspaper as a substrate presented more fungi than the sawdust. The genera Penicillium sp and Aspergillus sp can cause pathologies such as penicilliosis and aspergillosis, in addition to spots on the epidermis and eyes. According to the results, it is suggested the application of antifungals on the snake's epidermis, in order to avoid future cases of fungal diseases.

Key words: fungi, jararaca, captivity.

\section{http://dx.doi.org/: 10.5935/1981-2965.20210004}

Autor para correspondência. E.mail:* fbiancalana@ufpa.br Received for publication 10.01.2020; approved on 30.03.2020

1-Biólogo - eriveltonchaves366@gmail.com

2- Professora Doutora da Universidade Federal do Pará - UFPA - email: cardoso.leandra@ gmail.com 3- Professor Doutor da Universidade Federal do Pará - UFPA - email: biancalana.a@ gmail.com

4- Professora Doutora da Universidade Federal do Pará - UFPA - email: fbiancalana@ufpa.br

\section{Introdução}

No mundo estão descritas, atualmente, 3.378 espécies de serpentes distribuídas em 23 famílias (UETZ \& HOSEK, 2012). O Brasil possui uma riquíssima fauna de serpentes, responsável por $10 \%$ do total das espécies, tendo representantes de 375 espécies distribuídas em 9 famílias (MELGAREJO, 2009).
Desde o século XIX, começou-se a manter, reproduzir e criar serpentes, por curiosidade, para expor esses animais em zoológicos e museus ou pela necessidade de obtenção de seus venenos para pesquisa e produção de medicamentos. No início, de uma forma intuitiva e, posteriormente, de forma cada vez mais técnica, tentando reproduzir da melhor forma possível as 
condições ambientais necessárias, os serpentários vêm enfrentando o desafio de aprimorar a criação desses animais, possibilitando,

cada vez mais, uma maior independência de sua captura nos ambientes naturais (MELGAREJO, 2009).

A maioria dos cativeiros tenta imitar o local de origem desses animais e dessa forma isso pode afetar a vivência dessas serpentes, provocando o aparecimento de doenças geradas por estresse, distúrbios de comportamento e outros fatores. A maioria dessas serpentes mantidas e criadas em cativeiro, encontram um ambiente úmido, morno, ventilado e convivem com outros animais em cativeiro e dessa maneira podem ser expostos aos mais variados tipos de patógenos (MILLER et al., 2004); (BORGES, 2013).

Estas características favorecem a contaminação dos cativeiros com fungos filamentosos, dos quais muito são oportunistas de origem ambiental e têm sido identificados como causadores de micoses em serpentes (MILLER et al., 2004). Muitos destes fungos são considerados microrganismos da microbiota normal de répteis em cativeiro (Paré et al., 2003). Estes casos de doença por fungos em serpentes vêm ganhando destaque na literatura, pois normalmente doenças micóticas em serpentes podem ser fatais (COSTA et al. 2006).
$\mathrm{Na}$ maioria das vezes, essas afecções aparecem no período mais chuvoso do ano, devido à alta umidade e baixa temperatura, pois o animal fica com o metabolismo fragilizado e acabam desenvolvendo, principalmente, patologias como pneumonia e estomatite. Além disso, o manejo deficiente também é um fator de risco para a saúde desses animais (Bastos et al., 2005). Em representantes de Bothrops atrox cativas, a principal causa de afecções é a síndrome da má adaptação, que chega a levar mais de $80 \%$ dos animais com menos de dois anos a óbito, podendo desencadear a falta ou inibição total de apetite, emagrecimento, mesmo sendo alimentada, gerar a fragilidade dos tecidos que resulta em ulcerações cutâneas nos pontos de maior fricção, maior suscetibilidade a parasitoses e infecções causadas por microrganismos patogênicos (BASTOS et al., 2005). Infecções oportunistas ocorrem principalmente em animais silvestres imunodeprimidos, tendo a inalação como a principal rota de infecção para a maioria dos fungos (FRIEND et al., 1999).

Uma grande variedade de doenças fúngicas tem sido descritas ocorrendo nas variadas ordens existentes dentro da Classe Reptilia.

Essas afecções, geralmente estão relacionadas ao manejo inadequado desses animais em cativeiro, como alta umidade, 
superpopulações e acúmulos de detritos no ambiente (PARÉ, 2007).

$\mathrm{Na}$ literatura são encontradas descrições de casos de infecções por Fusarium spp. em répteis terrestres e semiaquáticos, em geral associadas a lesões de pele (Cabañes et al., 2014). Patologias de pele são comuns em répteis, especialmente quando mantidos em ambiente cativo. Essas dermatopatias podem ter origem infecciosa (fúngica, bacteriana, viral e parasitária) ou física, sendo as lesões traumáticas as principais apresentações clínicas na medicina de répteis (Cooper, 2006)). Fungos considerados saprófitos têm sido relatados como agentes etiológicos de micoses em serpentes. A espécie Aspergillus spp. foi encontrada em lesão pulmonar de uma fêmea de anaconda (Euncectes murinus) nascida em cativeiro (MILLER et al., 2004).

Mas os escassos trabalhos existentes diante a identificação da microbiota fúngica de animais, principalmente de répteis, referem-se a casos isolados carecendo de dados epidemiológicos a respeito da microbiota oral, ocular, habitante de tegumento, entre outras. Os principais relatos de micoses ou da presença de agentes fúngicos na microbiota de animais silvestres citam como principais representantes os fungos Aspergillus spp., Fusarium spp., Candida spp., Malassezia spp., Criptococcus spp. e os dermatófitos (Albano et al.,2009).

$\mathrm{Na}$ literatura ainda há poucos trabalhos que foquem exclusivamente nas doenças fúngicas que acometem essas serpentes e na região Amazônica, o número de trabalhos de cunho cientifico com essa temática é muito reduzido. Sendo assim, este estudo propôs identificar a microbiota fúngica presente em escamas de Bothrops atrox (Serpente-Viperidae) criadas em cativeiro buscando evidenciar qual espécie de fungos apresenta maior ocorrência na região dorsoventral, determinar se a presença de fungos está associada ao estágio de vida da serpente e também investigar se diferentes substratos e condições de armazenamento podem ter influência sobre os representantes fúngicos. Os dados obtidos poderão servir como base para novas pesquisas, onde poderá auxiliar no controle de diversas doenças provenientes dessas infecções, assim como a utilização e aplicação de tratamento adequado para os mais variados quadros e conhecer a microbiota que as serpentes podem apresentar durante sua vida livre.

\section{Materiais e métodos}

\section{Espécie-alvo}

A serpente Bothrops atrox (Linnaeus, 1758), também conhecida popularmente por jararaca, é uma espécie amplamente distribuída no bioma 
Amazônico, encontrada em florestas tropicais da América do Sul, compreendendo Brasil, Bolívia, Leste dos Andes, Equador, Peru, Venezuela, Ilhas Trinidad, Sudeste da Colômbia, Guiana, Suriname e Guiana Francesa. Localmente abundante e generalista quanto ao uso do hábitat (FRAGA et al., 2013).

Representantes da espécie Bothrops atrox possuem uma dentição do tipo solenóglifa, peçonhas sulcadas e articuladas localizadas anteriormente, de hábito terrícola, ativa durante o dia, mas seus hábitos são noturnos preferencialmente. É a serpente peçonhenta mais frequente da Amazônia, possuindo um grande poder de adaptação, suportando bem as alterações ambientais que estão ocorrendo e é a responsável pelo maior número de acidentes ofídicos da região (90\%) (ARAÚJO, 2013)

\section{Coleta de Dados}

As amostras de microbiota foram coletadas em 54 serpentes nascidas e criadas em cativeiro. As coletas foram realizadas em espécimes provenientes do plantel de serpentes do criadouro Centro Amazônico de Herpetologia, localizado no município de Benevides, nordeste do estado do Pará, Brasil. O serpentário abriga as serpentes de forma individualizadas, mantidas em estantes e acondicionadas em caixas de polipropileno. As caixas variam de $45 \times 32 \times 28 \mathrm{~cm}, 34 \times 22 \times 12 \mathrm{~cm}$ e $56 \times 37 \times 24$ $\mathrm{cm}$, dependendo do tamanho da serpente. Dentro deste ambiente também está localizado o espaço de triagem, onde o material foi coletado. A bancada de trabalho foi higienizada a cada espécime exposto e coletado.

Os animais utilizados são filhotes de Bothrops atrox nascidos em ninhadas de 3 serpentes-mães no ano de 2017 e 2018. Os espécimes estavam devidamente separados: filhotes nascidos no ano de 2017, por apresentarem maiores comprimentos corpóreos acondicionados em recipientes de polipropileno maiores, forrados com jornal. Os filhotes nascidos no ano de 2018 ocupavam pequenas vasilhas de plástico, com o substrato composto por serragem.

Os recipientes para a manutenção de serpentes devem reunir uma série de condições gerais, independente de peculiaridades, tais como o tipo e o tamanho da serpente a ser mantida, características referentes à sua confiabilidade, no sentido de ter uma construção sólida, em material resistente com acesso amplo, sistema de fechamento fácil e vedação total, além de um travamento seguro. A caixa deve, dentro do possível, possuir um visor para permitir uma fácil e rápida vistoria diária, além de se observar o posicionamento e atitudes da serpente antes de sua abertura para atividades de rotina e manuseio. Também 
devem ser práticos no manejo, além da necessária estabilidade e acomodação nas prateleiras ou suportes da sala. Finalmente, deve ser higiênica, permitindo limpeza e desinfecção rotineiras e ser dotada de um bom sistema de ventilação conforme Figura 1(MELGAREJO, 2009).
Devemos destacar que todas essas boas condições descritas por Melgarejo (2009) foram encontradas nas serpentes localizadas no Centro Amazônico de Herpetologia. Isto é, todos os indivíduos estavam e condições adequadas de armazenamento.

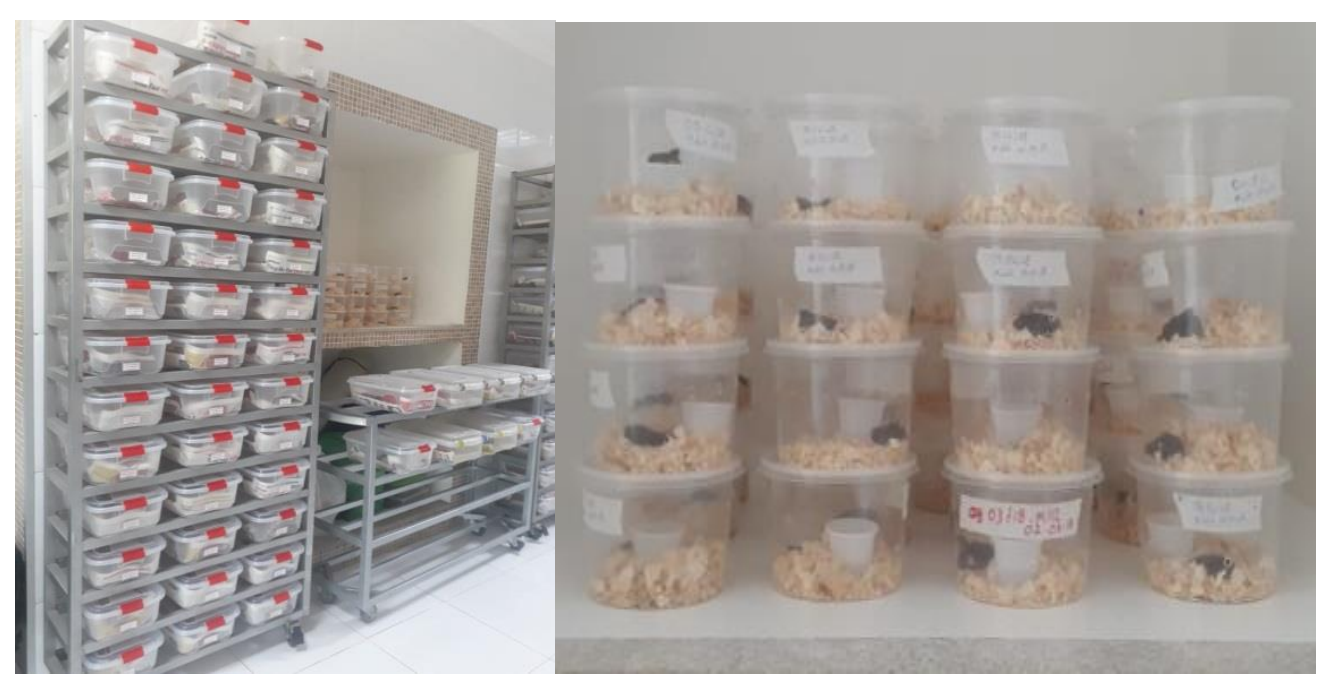

Figura 1- À esquerda, estante e caixas para o acondicionamento individual de serpentes jovens (substrato de jornal), nascidas em 2017. À direita, detalhe do recipiente de acondicionamento individual de serpentes jovens (substrato de serragem), nascidas em 2018 no Centro Amazônico de Herpetologia.

Para coleta das amostras, as serpentes foram imobilizadas e com o auxílio de um swab estéril foi feita a coleta passando o mesmo sobre as escamas do animal, fazendo movimentos na direção dorsoventral a partir da demarcação da cabeça até um pouco antes da cloaca do animal. Após o swab ser utilizado, o mesmo é selado, identificado de acordo com o código das serpentes e transportado em um recipiente de isopor (Figura 2). 


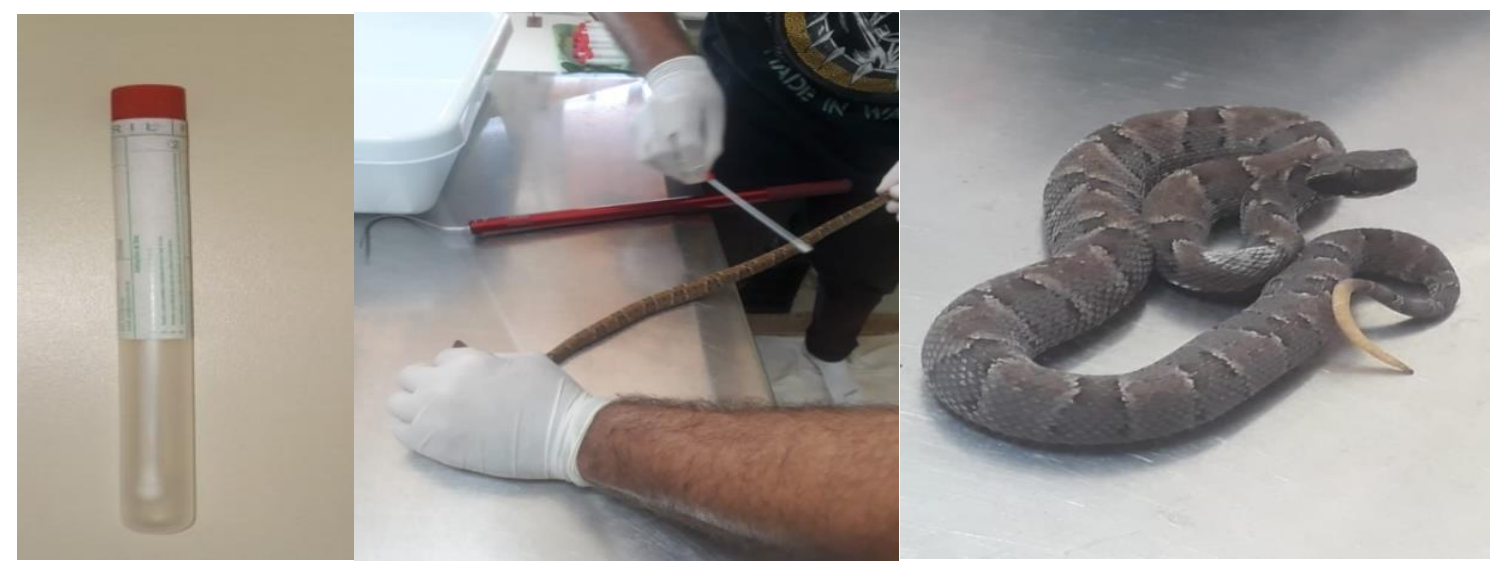

Figura 2 - À esquerda, Swab estéril utilizado. Ao centro, movimento de coleta. À direita, espécime na bancada de coleta, com mancha esbranquiçada, provocada pela proliferação de um fungo em sua epiderme.

\subsection{Isolamento e identificação de fungos}

Os processos de extração, cultivo e identificação da microbiota foram realizados no Laboratório de Microbiologia e Parasitologia da Universidade Federal do Pará, Campus Universitário do Marajó-Soure.
Realizamos a técnica de Pour Plate em ágar Sabouraud-Dextrose.

Em 60 placas de Petri os swabs foram esfregados, as placas semeadas foram incubadas à 27 graus durante 0 período de 6 a 15 dias

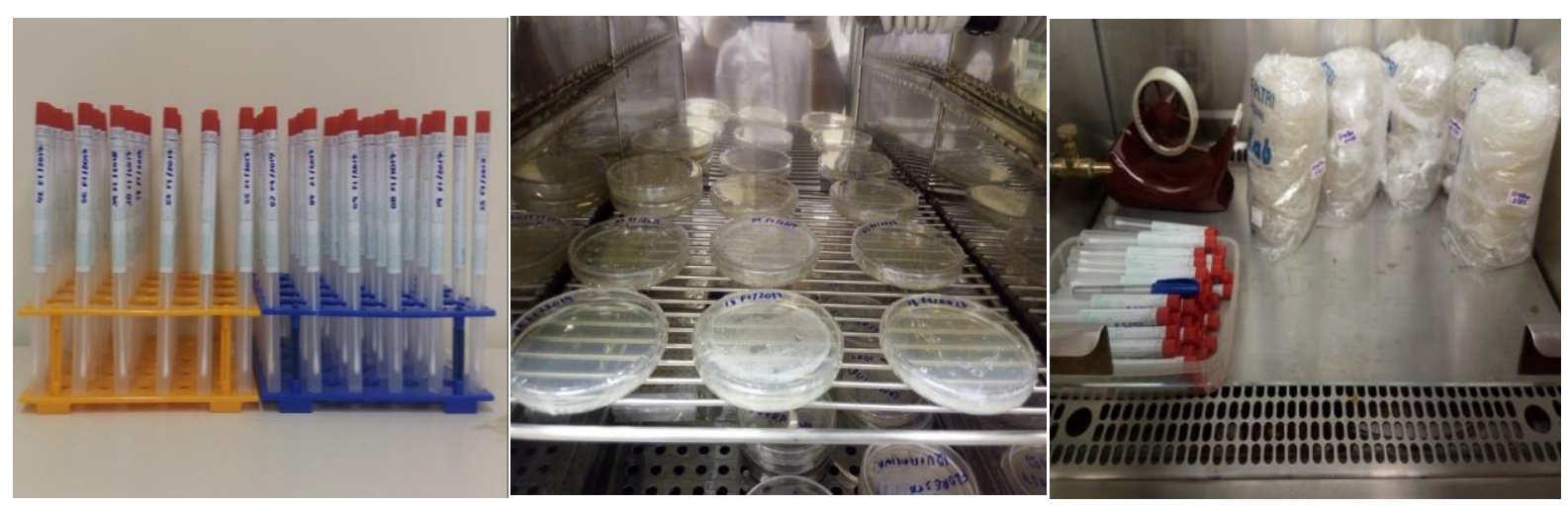

Figura 3 - À Direita, swabs utilizados na coleta. Centro, placas na estufa após a semeadura. À Esquerda, materiais usados para semeadura dos swabs nas placas de Petri descartáveis com meio de cultura ágar batata. 
Após o crescimento dos fungos isolados, deu-se início a anotação das características das colônias, como a sua coloração, textura e topografia para auxílio na posterior identificação macroscópica. Após o crescimento dos fungos, foi feita uma lâmina e colocada uma gota de azul de lactofenol, as lâminas prontas foram observadas ao microscópio óptico (aumento de 40X). As hifas e corpos de frutificação observados também foram fotografados. Somente 50 placas apresentaram o crescimento de colônias fúngicas ou de leveduras. A identificação das culturas de fungos foi realizada através da observação das características macromorfológicas, micromorfológicas e quando necessária observação das características fisiológicas. As características macromorfológicas analisadas foram a forma, topografia e a coloração das colônias (DE HOOG et al., 2000; LACAZ et al., 2002).

\section{Resultados e Discussão}

As 50 placas de Petri que apresentaram crescimento de colônias resultaram na produção de 79 lâminas, que foram coradas com azul de lactofenol e identificadas de acordo com o código de cada serpente (Exemplificação nas Figuras 4 a 9).

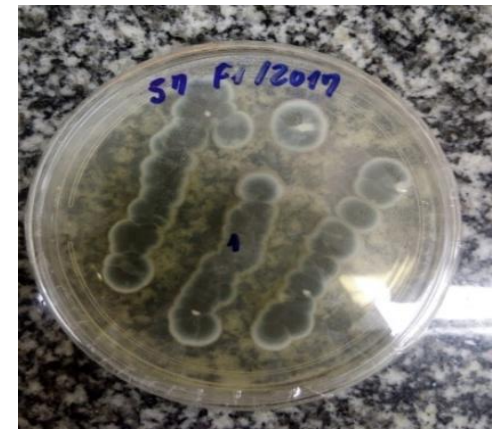

Figura 4- Placa 57 F1/2017: placa com crescimento de colônias.

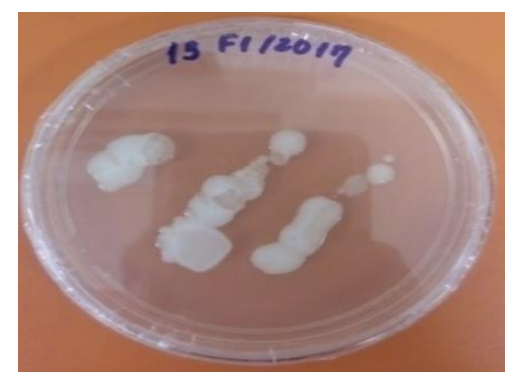

Figura 7 - Placa 13 F1/2017: placa com crescimento de leveduras e de fungos.

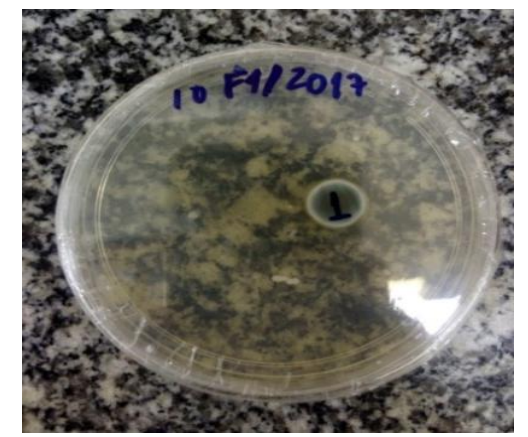

Figura 5- Placa 10 F1/2017: placa com crescimento de uma colônia

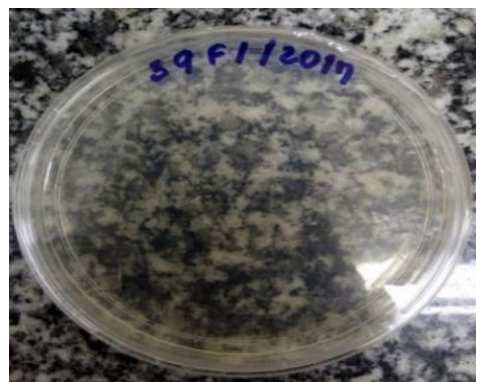

Figura 8 - Placa 39 F1/2017: placa sem o crescimento de colônias ou levedura.

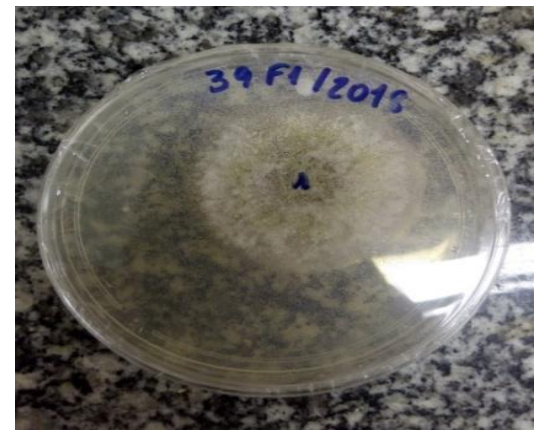

Figura 6- Placa 39 F1/2018: placa com crescimento de uma colônia.

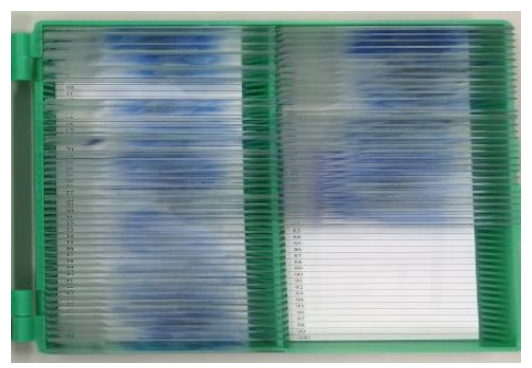

Figura 9 - Laminário com o material produzido. 
Com o resultado da análise das lâminas foi possível observar os seguintes gêneros fúngicos: Penicillium sp., Aspergillus sp., Phoma sp., Rhizophus sp., onde os dois primeiros foram os mais representativos. $\mathrm{O}$ fungo do gênero Penicillium sp. estava presente em 29 placas, Aspergillus sp. em 27 das placas,
Phoma sp. em apenas uma, Rhizophus sp. em duas placas.

O número de placas que apresentaram colônias onde não foi possível a identificação do material, já que não houve crescimento de nenhum tipo de organismo, foi de 20 no total

( Tabela 1).

Tabela 1 - Identificação das lâminas com a identificação, quando possível, do fungo encontrado em Bothrops atrox, assim como a idade e o substrato em que as serpentes estavam no momento da coleta.

\begin{tabular}{|c|c|c|c|}
\hline ID da serpente & Ano de & Substrato & Fungos encontrados \\
\hline 02 F1/2017 & 2017 & Jornal & Rhizophus sp \\
\hline 03 F1/2017 & 2017 & Jornal & Aspergillus sp. \\
\hline $04 \mathrm{~F} 1 / 2017$ & 2017 & Jornal & Aspergillus sp. \\
\hline $05 \mathrm{~F} 1 / 2017$ & 2017 & Jornal & Aspergillus sp. \\
\hline 06 F1/2017 & 2017 & Jornal & Aspergillus sp., Penicillium sp \\
\hline 07 F1/2017 & 2017 & Jornal & Penicillium sp. \\
\hline $08 \mathrm{~F} 1 / 2017$ & 2017 & Jornal & Penicillium sp. \\
\hline $09 \mathrm{~F} 1 / 2017$ & 2017 & Jornal & Rhizophus sp., Penicillium $s p$ \\
\hline $10 \mathrm{~F} 1 / 2017$ & 2017 & Jornal & Penicillium sp. \\
\hline $11 \mathrm{~F} 1 / 2017$ & 2017 & Jornal & Penicillium sp. \\
\hline $12 \mathrm{~F} 1 / 2017$ & 2017 & Jornal & Aspergillus sp., Penicillium sp \\
\hline $13 \mathrm{~F} 1 / 2017$ & 2017 & Jornal & Penicillium sp. \\
\hline $14 \mathrm{~F} 1 / 2017$ & 2017 & Jornal & Aspergillus sp., Penicillium sp \\
\hline $15 \mathrm{~F} 1 / 2017$ & 2017 & Jornal & Penicillium sp. \\
\hline 16 F1/2017 & 2017 & Jornal & Aspergillus sp., Penicillium sp \\
\hline 17 F1/2017 & 2017 & Jornal & Penicillium sp. \\
\hline $18 \mathrm{~F} 1 / 2017$ & 2017 & Jornal & Penicillium sp. \\
\hline $19 \mathrm{~F} 1 / 2017$ & 2017 & Jornal & Não houve frutificação \\
\hline $20 \mathrm{~F} 1 / 2017$ & 2017 & Jornal & Aspergillus sp. \\
\hline $21 \mathrm{~F} 1 / 2017$ & 2017 & Jornal & Aspergillus sp. \\
\hline $22 \mathrm{~F} 1 / 2017$ & 2017 & Jornal & Penicillium sp. \\
\hline $23 \mathrm{~F} 1 / 2017$ & 2017 & Jornal & Aspergillus sp., Penicillium sp \\
\hline $25 \mathrm{~F} 1 / 2017$ & 2017 & Jornal & Aspergillus sp., Penicillium sp \\
\hline $26 \mathrm{~F} 1 / 2017$ & 2017 & Jornal & Aspergillus sp. \\
\hline $27 \mathrm{~F} 1 / 2017$ & 2017 & Jornal & Aspergillus sp. \\
\hline $28 \mathrm{~F} 1 / 2017$ & 2017 & Jornal & Aspergillus sp. \\
\hline $29 \mathrm{~F} 1 / 2017$ & 2017 & Jornal & Aspergillus sp., Penicillium sp \\
\hline $30 \mathrm{~F} 1 / 2017$ & 2017 & Jornal & Penicillium sp. \\
\hline $31 \mathrm{~F} 1 / 2017$ & 2017 & Jornal & Phoma sp. \\
\hline 32 F1/2017 & 2017 & Jornal & Aspergillus sp., Penicillium sp \\
\hline 33 F1/2017 & 2017 & Jornal & Penicillium sp. \\
\hline $34 \mathrm{~F} 1 / 2017$ & 2017 & Jornal & Aspergillus sp. \\
\hline
\end{tabular}




\begin{tabular}{|c|c|c|c|}
\hline 37 F1/2017 & 2017 & Jornal & Aspergillus sp. \\
\hline 38 F1/2017 & 2017 & Jornal & Aspergillus sp. \\
\hline $39 \mathrm{~F} 1 / 2017$ & 2017 & Jornal & Não houve frutificação \\
\hline $41 \mathrm{~F} 1 / 2017$ & 2017 & Jornal & Penicillium sp. \\
\hline 42 F1/2017 & 2017 & Jornal & Não houve frutificação \\
\hline 43 F1/2017 & 2017 & Jornal & Não houve frutificação \\
\hline 45 F1/2017 & 2017 & Jornal & Penicillium sp. \\
\hline 46 F1/2017 & 2017 & Jornal & Penicillium sp. \\
\hline $47 \mathrm{~F} 1 / 2017$ & 2017 & Jornal & Aspergillus sp. \\
\hline $51 \mathrm{~F} 1 / 2017$ & 2017 & Jornal & Aspergillus sp., Penicillium sp \\
\hline 53 F1/2017 & 2017 & Jornal & Aspergillus sp. \\
\hline $54 \mathrm{~F} 1 / 2017$ & 2017 & Jornal & Penicillium sp. \\
\hline $55 \mathrm{~F} 1 / 2017$ & 2017 & Jornal & Aspergillus sp., Penicillium $\mathrm{sp}$ \\
\hline $56 \mathrm{~F} 1 / 2017$ & 2017 & Jornal & Aspergillus sp., Penicillium sp \\
\hline 57 F1/2017 & 2017 & Jornal & Penicillium sp. \\
\hline $58 \mathrm{~F} 1 / 2017$ & 2017 & Jornal & Aspergillus sp. \\
\hline $59 \mathrm{~F} 1 / 2017$ & 2017 & Jornal & Aspergillus sp. \\
\hline 03 F1/2018 & 2018 & Serragem & Penicillium sp. \\
\hline 05 F1/2018 & 2018 & Serragem & Aspergillus sp. \\
\hline $32 \mathrm{~F} 1 / 2018$ & 2018 & Serragem & Não houve crescimento \\
\hline 35 F1/2018 & 2018 & Serragem & Não houve crescimento \\
\hline $39 \mathrm{~F} 1 / 2018$ & 2018 & Serragem & Não houve crescimento \\
\hline $47 \mathrm{~F} 1 / 2018$ & 2018 & Serragem & Não houve crescimento \\
\hline
\end{tabular}

Todos os filhotes do ano de 2017 estavam acondicionados em recipientes de polipropileno contendo como substrato o jornal, mantendo o ambiente sempre limpo, totalizando 50 recipientes cada um contendo uma serpente. Já os filhos do ano de 2018 estavam acondicionados em vasilhas de plástico, contendo como substrato serragem proveniente do corte de árvores, totalizando 6 vasilhas, cada uma também contendo um espécime.

Filhotes do ano de 2017 que estavam em recipientes com substrato de jornal, apresentaram presença de Penicillium sp., Aspergillus sp., Phoma sp. e Rhizopus sp. Já os filhotes do ano de 2018 que estavam em vasilhas que continham como substrato serragem, apresentaram a presença de Penicillium sp. e Aspergillus sp.

Observamos que o Centro Amazônico de Herpetologia apresenta uma rotina bastante detalhada para limpeza, do local e seus instrumentos, dos recipientes e das vasilhas, substituição de substrato, troca da água e momento de alimentação das serpentes.

Os fungos identificados são provenientes do ambiente que rodeia as serpentes em questão, desde o solo, ar, das suas próprias fezes e também de matéria 
morta em decomposição, mas esse contato com a microbiota dessas serpentes poderia gerar graves quadros de doenças micóticas (Lacaz, 1991). A região Amazônica sofre muita influência no seu clima, principalmente na estação chuvosa, podendo aumentar a frequência de infecções micóticas (FARIAS, 2019).

Neste estudo foi observada a prevalência do gênero Penicillium sp. em muitas das amostras. Segundo Frias (2008), esse fungo está presente principalmente no solo, porém o mesmo não apresenta referência na literatura de colonização ou infecção em serpentes. Mas há casos da presença dele em amostras em pelos de mamíferos, apontados como agentes de dermatofitose, os sapróbios, geralmente encontrados no ambiente e outros materiais e comumente isolados de cães e gatos (MANCIANTI, 1996).

O segundo mais prevalente foi o fungo do gênero Aspergillus sp, o qual é encontrado frequentemente no solo, detritos vegetais, ar atmosférico causando a conhecida pneumonia fúngica, além de ser um agente etiológico que pode agravar quadros de lesões humanas e de animais (LACAZ, 1991). Este é considerado um agente oportunista por excelência. Miller $e t$ al. (2004) isolaram este gênero de lesões pulmonares de uma anaconda nascida e criada em cativeiro, a qual já havia apresentado histórico clínico de infecção micótica cutânea.

Ainda houve presença de Phoma sp. que é um fungo comum de solo e um patógeno de plantas (Kirk 2008). Não havendo relatos de infecções de quaisquer naturezas em répteis. Sua presença nos resultados pode ser ligada ao fato de que os substratos que são utilizados, são de origem vegetal (jornal e serragem) causando assim o contato desse fungo com a microbiota das serpentes.

Houve a presença de Rhizophus sp. um fungo saprófito comum e parasita facultativo de frutos, vegetais e fezes de animais em decomposição. Podendo em alguns casos serem agentes oportunistas infecciosos da zigomicose humana e em animais (Kirk et al 2001).Há casos da presença dele em amostras em pelos de mamíferos, apontados como agentes de dermatofitose, os sapróbios, geralmente encontrados no ambiente e outros materiais e comumente isolados de cães e gatos, elementos que se encontram no solo principalmente e que podem gerar casos de doenças na pele humana (MANCIATI, 1996).

Alguns fungos foram isolados, porém não foi possível a identificação, sugere-se que este resultado encontrado ocorreu devido à dificuldade na desses fungos produzirem corpos de frutificação 
dos mesmos, e assim possibilitar a identificação.

Os resultados deste trabalho são semelhantes aos que Costa 2006, que fez um levantamento de fungos filamentosos na epiderme de Crotallus durissus terrificcus (Cascavel) criadas em cativeiro obtendo resultados para a prevalência do gênero Aspergillus sp. (25\%) e também do fungo do gênero Penicillium sp. (20\%). Os resultados de trabalhos anteriores mostram a presença dos fungos do gênero Aspergillus sp. e Penicillium sp., que podem provocar doenças respiratórias principalmente.

O substrato apropriado deve forrar o piso da caixa para proporcionar o conforto do animal, pode ser utilizado papelão ondulado, maravalha ou jornal. Um refúgio, que pode ser um tijolo oco, um vaso de planta furado e invertido, um tronco oco ou um canudo de papel pode ser utilizado também, que dará conforto ao animal e evitará estresse excessivo (MELGAREJO, 2009). No Centro Amazônico de Herpetologia são utilizados como substrato o jornal (filhotes com um ano de nascimento, jovens e adultos) e serragem (filhotes com menos de um ano de nascimento), que proporcionam um espaço agradável para as serpentes e que não gerem tanto estresse.
Filhotes nascidos no ano de 2018 podem ter apresentado uma microbiota fúngica mais reduzida, devido ao fato da serragem que é utilizada como substrato, passar por procedimentos de esterilização por baixa temperatura, diferentemente dos filhotes do ano de 2017 que tem como substrato o jornal, onde os mesmos apresentaram mais diversidade em sua microbiota, devido o substrato onde são acondicionadas não ser submetido a nenhum tipo de procedimento de limpeza ou esterilização. Isso poderia implicar também no número de representantes fúngicos que possam estar presentes nos recipientes onde as serpentes estão inseridas, onde indivíduos mais novos tendem a ser mais suscetíveis a desenvolverem doenças causadas por agentes etiológicos. Além do procedimento de desinfecção por baixa temperatura ou uso de álcool $70 \%$, poderiam ser adotados métodos de utilização de luz ultravioleta e produtos antifúngicos.

Fungos podem se proliferar em jornal, papeis, couro e outros materiais, causam manchas no substrato e podem provocar doenças na epiderme e pulmonares em mamíferos principalmente (CASSARES et al, 2000). Nesse trabalho o jornal como substrato apresentou maior 
ocorrência fúngica, já que o mesmo não passa por nenhum procedimento de limpeza, podendo ocasionar nas serpentes doenças provenientes desses fungos.

Este trabalho nos permitiu identificar os possíveis patógenos fúngicos encontrados em jararacas (B. atrox) em cativeiro e assim possibilitar tratamento adequado as serpentes. Destacamos que as serpentes se encontravam em ótimo estado de acondicionamento e limpeza. Essas condições foram refletidas em nossos resultados, já que poderíamos ter encontrados muito mais fungos, casos esses procedimentos não fossem rotineiros.

Alguns fungos, são possíveis agentes causadores de doenças em animais e podem vir a causar alguma enfermidade as serpentes. Com a identificação desses patógenos, o proprietário do serpentário pode administrar o tratamento antifúngico adequado, caso as serpentes venham a manifestar sintomas dessas doenças.

\section{Conclusões}

Foi observada a prevalência do gênero Penicillium sp. somando 29 amostras, um fungo presente no solo, porém não apresenta referência na literatura de colonização ou infecção em serpentes. Os filhotes do ano de 2017 apresentaram maior presença de fungos, do que os filhotes nascidos no ano 2018, dessa maneira serpentes mais velhas apresentam uma microbiota fúngica mais diversa. $\mathrm{O}$ jornal como substrato apresentou mais fungos, já que não recebe nenhum tipo de procedimento para esterilização, a serragem mesmo sendo processada e esterilizada, também apresentou fungos.

Os resultados sugerem que o tipo de manejo adotado dentro do cativeiro, visa buscar a eliminação da maioria dos agentes etiológicos como os fungos. Sem esses procedimentos poderia haver a presença de mais fungos nesse local.

Como sugestão pode haver a aplicação de antifúngicos na epiderme das serpentes, para assim evitar futuros casos de doenças fúngicas dentro do Centro de Herpetologia.

\section{Agradecimentos:}

Agradecemos ao Centro Amazônico de Herpetologia - CAH por nos permitir realizar as pesquisas nas serpentes mantidas no criadouro.

\section{Referências bibliográficas}

ALBANO, A..P.N. Fungos e micoses em animais silvestres recebidos por Centros de Triagem. Pelotas, 2009. - 82p.

Dissertação de Mestrado em Sanidade Animal. Faculdade de Veterinária. Universidade Federal de Pelotas. Pelotas, RS, 2009. 
ARAÚJO, A.J.G.; BASTOS, O.M.P.; SOUZA, M.A.J.; OLIVEIRA, J.C. Ocorrência de onicomicoses em pacientes atendidos em consultórios dermatológicos na cidade do Rio de Janeiro, Brasil. Bras.Dermtol., v. 78, p. 445 - 455, 2003.

BASTOS, E.G. DE M.; ARAÚJO, A.F.B. DE; SILVA, H.R. DA. Records of the rattlesnakes Crotalus durissus terrificus (Laurenti) (Serpentes, Viperidae) in the State of Rio de Janeiro, Brazil: a possible case of invasion facilitated by deforestation. Revista Brasileira de Zoologia, v. 22, n. 3, p. 812-815, 2005.

BORGES, R.C.; OLIVEIRA, A.; COSTA, R.M.M.C. Serpentes peçonhentas: identificação e procedimentos em acidentes - uma analise dos livros didáticos do Ensino Fundamental e Médio. São Paulo: Atheneu, v.5,2013, $134 \mathrm{p}$.

CABAÑES, F.J.; Sutton, D,A.; GUARRO, J. Chrysosporium-Related Fungi and Reptiles: A Fatal Attraction, Veterinary Mycology Group, Department of Animal Health and Anatomy, Spain. PLOS Pathogens, v.10, p.1-4,2014.

CASSARES, N.C.; MOI, C. Como fazer conservação preventiva em arquivos e bibliotecas. Arquivo do Estado/Imprensa Oficial. 5 ed. São Paulo. 2000, 70p.
COOPER, J.E. Dermatology. In: MADER, D.R. Reptile, Medicine and Surgery. 2. ed. Florida: Marathon, p. 196-215, 2006.

COSTA, A.C.B.P.; TEODORO, G.R.; OLIVEIRA， F.E.; PEREIRA， C.A.; CROSARIOL, S.K. Levantamento de fungos filamentosos presentes em escamas de Crotallus durissus terrificcus criadas em cativeiro. In: X Encontro Latino Americano de Iniciação Científica e VI Encontro Latino Americano de PósGraduação - Universidade do Vale do Paraíba, São José dos Campos. Resumos. 2006, p.2249-2252.

DE HOOG, G.S.; GUARRO, J.; GENÉ, J.; FIGUERAS, M.J. Atlas of Clinical Fungi. 2.ed. Rio de Janeiro: Guanabara, 2000, 1160p.

FARIAS A.N.; BIANCALANA A.; BIANCALANA F.S. Ocorrência de fungos demáceos em farpas de portões de madeira, no município de Soure, Pará. Revista Ouricuri, v.9, n.2. p.011-24, 2019.

FRAGA, R.; LIMA, A.P.; PRUDENTE, A.L. \& MAGNUSSON, W.E. Guia de cobras da região de Manaus - Amazônia Central. Manaus, AM: Editora INPA. 2013,303 p. 
FRIAS， D.F.R.; ANDREANI， D.I.K. Isolamento e identificação de fungos associados à dermatofitose e dermatomicose em cães. Tese de Doutorado em Zoologia - Departamento de Medicina Veterinária Preventiva e Reprodução Animal, - UNESP -Faculdade de Ciências Agrárias e Veterinárias. Revista CES / Medicina Veterinária y Zootecnia, São Paulo, V. 03, n. 2, p. 58-63, jul. 2008.

FRIEND, M.; FRANSON, J.C.; CIGANOVICH, E.A. Field manual of wildlife diseases: general field procedures and diseases of birds / Biological Resources, Division (Information and technology report; 1999001). Washington, D.C, 1999. 438p.

KIRK, P.M.; CANNON, P.F.; DAVID, J.C.; STALPERS, J.A. Ainsworth \& Bisby's Dictionary of the Fungi. 9 ed. Oxon, Ucrânia (UK): CAB International.. 2001, 452p.

KIRK,P.M.; CANNON, P. F.; MINTER, D.W.; STALPERS, J. A. Dictionary of the Fungi. 10ed. Wallingford: CABI. 2008, $524 \mathrm{p}$.
LACAZ, C.S.; PORTO, E.; MARTINS, J.E.C.; HEINS - VACCARI E.M.; MELO, N.T. Tratado de micologia médica. 9 ed. São Paulo, Brasil: Sarvier 2012, 1104p.

LACAZ, C.S., PORTO, E., HEINSVACCARI, E.M., MELO, N.T. Guia para Identificação: Fungos, Actinomicetos, Algas de Interesse Médico. São Paulo: Sarvier, 1998, 445p.

MANCIANTI, F.P.R. Isolation of keratinophilic fungi from the floors of private veterinary clinics in Italy. Veterinary Research Communications; 20:161-166, 1996.

MELGAREJO, A.R. Serpentes Peçonhentas do Brasil. In: CARDOSO, J.L.C.; FRANÇA, F.O.S.; WEN, F.H.; MÁLAQUE, C.M.S.; HADDAD JR., V. (Eds.). Animais Peçonhentos no Brasil: Biologia, Clínica e Terapêutica dos Acidentes. 2 ed. São Paulo: Sarvier, 2009,488p.

MILLER, D.L. et al. Cutaneous and pulmonary mycosis in green anacondas (Eunectes murinus). J. Zoo. Wildl.Med. v.35, n.4, p.557-561, 2004. 
PARÉ, J.A. et al. Cutaneous mycobiota of captive squamate reptiles with notes on the scarcity of Chrysosporium anamorph of Nannizziopsis vriesii. J. Herpetol. Med. Sug. v.13, p.10-15, 2003.

PARÉ, J.A.; JACOBSON, E.R. Mycotic Diseases of Reptiles. In: JACOBSON, Elliott R. (Ed.). Infectious diseases and pathology of reptiles. Gainesville: Crc Press,. Cap. 11. p. 541-584, 2007.

UETZ, P. \& HOŠEK, J. (Eds.).The Reptile Database. Available from: http://www.reptile-

database.org/reptarium.cz Acess: jul, 15, 2018. 